\title{
Phase II study of pemetrexed and carboplatin plus bevacizumab as first-line therapy in malignant pleural mesothelioma
}

G L Ceresoli ${ }^{*}, 1$, P A Zucali ${ }^{2}$, M Mencoboni ${ }^{3}$, M Botta $^{4}$, F Grossi ${ }^{5}$, D Cortinovis ${ }^{6}$, N Zilembo ${ }^{7}$, C Ripa ${ }^{1}$, M Tiseo ${ }^{8}$, A G Favaretto ${ }^{9}$, H Soto-Parra ${ }^{10}$, F De Vincenzo ${ }^{2}$, A Bruzzone ${ }^{3}$, E Lorenzi $^{2}$, L Gianoncelli $^{2}$, B Ercoli ${ }^{2}$, L Giordano $^{11}$ and A Santoro ${ }^{2}$

${ }^{1}$ Department of Medical Oncology, Cliniche Humanitas Gavazzeni, Bergamo, Italy; ${ }^{2}$ Department of Oncology, Humanitas Cancer Center, Rozzano (Milan), Italy; ${ }^{3}$ Department of Oncology, Ospedale Villa Scassi, Sampierdarena, ASL 3 Genovese, Genova, Italy; ${ }^{4}$ Department of Medical Oncology, Ospedale S. Spirito, Casale Monferrato, Italy; ${ }^{5}$ Lung Cancer Unit, National Institute for Cancer Research, Genova, Italy; ${ }^{6}$ Department of Medical Oncology, Ospedale San Gerardo, Monza, Italy; ${ }^{7}$ Department of Medical Oncology, National Cancer Institute, Milan, Italy; ${ }^{8}$ Department of Medical Oncology, Ospedale Maggiore, Parma, Italy; ${ }^{9}$ Department of Medical Oncology, Istituto Oncologico Veneto IRCCS, Padova, Italy; ${ }^{10}$ Department of Medical Oncology, Ospedale Universitario Vittorio Emanuele, Catania, Italy and ${ }^{11}$ Biostatistic Unit, Humanitas Cancer Center, Rozzano (Milan), Italy

Background: The aim of this open label phase II study (NCT00407459) was to assess the activity of the vascular endothelial growth factor (VEGF) inhibitor bevacizumab combined with pemetrexed and carboplatin in patients with previously untreated, unresectable malignant pleural mesothelioma (MPM).

Methods: Eligible patients received pemetrexed $500 \mathrm{mg} \mathrm{m}^{-2}$, carboplatin area under the plasma concentration-time curve (AUC) $5 \mathrm{mg} \mathrm{ml}^{-1}$ per minute and bevacizumab $15 \mathrm{mg} \mathrm{kg}^{-1}$, administered intravenously every 21 days for six cycles, followed by maintenance bevacizumab. The primary end point of the study was progression-free survival (PFS). A $50 \%$ improvement in median PFS in comparison with standard pemetrexed/platinum combinations (from 6 to 9 months) was postulated.

Results: Seventy-six patients were evaluable for analysis. A partial response was achieved in 26 cases (34.2\%, 95\% Cl 23.7-46.0\%). Forty-four (57.9\%, 95\% Cl 46.0-69.1\%) had stable disease. Median PFS and overall survival were 6.9 and 15.3 months, respectively. Haematological and non-haematological toxicities were generally mild; however, some severe adverse events were reported, including grade 3-4 fatigue in $8 \%$ and bowel perforation in $4 \%$ of patients. Three toxic deaths occurred.

Conclusion: The primary end point of the trial was not reached. However, due to the limitation of a non-randomised phase II design, further data are needed before drawing any definite conclusion on the role of bevacizumab in MPM.

Malignant pleural mesothelioma (MPM) is an aggressive tumour with a poor prognosis. Only a minority of patients are eligible for multimodality therapy including surgery (Tsao et al, 2009; Scherpereel et al, 2010). Following the results of a large phase III trial, the combination of cisplatin and pemetrexed has been established as the standard of care for unresectable MPM
(Vogelzang et al, 2003). Carboplatin has the potential advantages of a better side effect profile and ease of administration. The combination of pemetrexed and carboplatin was found to be synergistic in preclinical models and active and well tolerated in a phase I trial as well as in two large phase II studies (Hughes et al, 2002; Ceresoli et al, 2006; Castagneto et al, 2008). These data were

*Correspondence: Dr GL Ceresoli; E-mail: giovanni_luca.ceresoli@gavazzeni.it

Received 24 February 2013; revised 10 June 2013; accepted 22 June 2013; published online 16 July 2013

(c) 2013 Cancer Research UK. All rights reserved 0007-0920/13 
confirmed by the results of an International Extended Access Program (Santoro et al, 2008). Unfortunately, nearly all MPM patients progress during or after first-line treatment. Second-line chemotherapy is being increasingly used in clinical practice, but to date there is no standard approach for this growing population of patients (Ceresoli et al, 2010). As a whole, currently available therapies still appear to have modest results, and new treatment strategies are eagerly awaited.

Preclinical studies have clearly shown that angiogenesis has a key role in the biology of MPM (Zucali et al, 2011). Vascular endothelial growth factor (VEGF) stimulates MPM cells growth in vitro in a dose-dependent manner and this growth has shown to be inhibited by anti-VEGF antibodies (Strizzi et al, 2001). Malignant pleural mesothelioma patients have among the highest circulating VEGF levels of any solid tumour, and high VEGF levels represent a poor prognostic factor in this disease (Kumar-Singh et al, 1999; Yasumitsu et al, 2010). Angiogenesis inhibitors, particularly bevacizumab, have therefore been studied and are still under evaluation in several trials in MPM, both in the first-line and in the pretreated patient setting (Ceresoli and Zucali, 2012). The results of a multicentre, double-blind, placebo-controlled randomised phase II trial of cisplatin-gemcitabine plus bevacizumab or placebo in patients with MPM have been recently reported (Kindler et al, 2012). In that study, the addition of bevacizumab did not significantly improve response rate, progression-free survival (PFS) or overall survival (OS). Another multicentre single-arm phase II study of the combination of cisplatin and pemetrexed plus bevacizumab in MPM patients failed to meet the primary end point of a 33\% improvement in PFS rate at 6 months compared with historical controls treated with cisplatin and pemetrexed alone (Dowell et al, 2012).

We report here the final results of a multicentre, open label phase II study designed to explore the efficacy of the combination of pemetrexed and carboplatin with bevacizumab as front-line therapy in patients with unresectable MPM.

\section{PATIENTS AND METHODS}

Patient selection. Patients were eligible if they had histologically proven MPM and unresectable disease according to an MPMexperienced surgeon. The presence of measurable and/or evaluable lesions according to modified RECIST criteria (Byrne and Nowak, 2004) was mandatory. Eligibility criteria included age $>18$ years and Eastern Cooperative Oncology Group (ECOG) performance status $(\mathrm{PS}) \leqslant 1$. An adequate bone marrow reserve was required, with absolute neutrophil count $\geqslant 1.5 \times 10^{9}$ per litre, platelets $\geqslant 100 \times 10^{9}$ per litre and haemoglobin $\geqslant 9 \mathrm{~g} \mathrm{dl}^{-1}$. Creatinine clearance, calculated by the Cockroft and Gault formula, had to be $\geqslant 50 \mathrm{ml} \mathrm{min}^{-1}$, bilirubin $\leqslant 1.5$-fold the upper limit of normal (ULN), and alanine aminotransferase or aspartate aminotransferase $\leqslant 2.5$-fold ULN. A baseline urine dipstick with proteinuria $<2+$ was required. Patients discovered to have $\geqslant 2+$ proteinuria had to undergo a $24-\mathrm{h}$ urine collection and demonstrate $\leqslant 1 \mathrm{~g}$ of protein per $24 \mathrm{~h}$. Prior systemic or intracavitary chemotherapy, documented brain metastases, serious comorbidities or other malignancies were not allowed. Patients with uncontrolled hypertension, serious non-healing wound or ulcer, evidence of bleeding diathesis or coagulopathy, or major surgical procedure, open biopsy, or significant traumatic injury within 28 days before study treatment start were not eligible for the trial. Patients were also excluded if they were currently on treatment with anti-coagulants, high-dose aspirin $\left(>325 \mathrm{mgday}^{-1}\right.$ ) or other medications known to predispose to gastrointestinal ulceration.

The study was conducted after approval by the ethical review board of each participating centre. Recommendations of the
Declaration of Helsinki for biomedical research involving human subjects were also followed. Written informed consent was obtained from each patient before entering the study.

Study design. The study was planned as a multicentre, open label phase II trial of the combination of pemetrexed, carboplatin and bevacizumab as front-line treatment in patients with MPM. Patients were enrolled prospectively from 10 Italian Institutions. The primary end point of the study was PFS. Secondary end points included toxicity, response rate and OS, as well as the evaluation of PFS and OS according to pretreatment serum VEGF levels. The trial was registered at www.clinicaltrials.com, with the number NCT00407459.

Treatment. Pemetrexed was administered intravenously at a dose of $500 \mathrm{mg} \mathrm{m}^{-2}$ over $10 \mathrm{~min}$, followed by carboplatin, administered over $1 \mathrm{~h}$ intravenous infusion at an area under the plasma concentration-time curve (AUC) of $5 \mathrm{mg} \mathrm{ml}^{-1}$ per minute and by bevacizumab, delivered as a $15 \mathrm{mg} \mathrm{kg}^{-1}$ intravenous infusion. Bevacizumab was administered initially over a 90 -min period. If the first infusion was well tolerated, then all subsequent infusions were delivered over $30 \mathrm{~min}$.

All drugs were given on day 1, every 21 days. Treatment was repeated for a maximum of six cycles or until progression or unacceptable toxicity. Patients without disease progression and/or severe toxicities received maintenance bevacizumab for a maximum of 1 year. All patients received during chemotherapy standard supplementation with folic acid and vitamin $B_{12}$. Dexamethasone, at a dose of $4 \mathrm{mg}$ twice daily, was given orally the day before, the day of, and the day after each chemotherapy. Salicylates and non-steroidal anti-inflammatory agents were not allowed the 2 days before, the day of, and the 2 days after treatment. Standard anti-emetic prophylaxis with intravenous $5-\mathrm{HT}_{3}$ antagonists was used.

Dose adjustments at the start of a subsequent cycle of therapy were based on haematologic and non-haematologic toxicity observed during the preceding course, according to protocolspecified guidelines. Dose delays up to 42 days were permitted to allow recovery from toxicity.

Patient assessment. Baseline assessment included a complete medical history and physical examination, complete blood cell counts and chemistries, and creatinine clearance. A chest and abdomen CT scan was performed at baseline and repeated every two cycles until the end of chemotherapy and every three cycles during maintenance bevacizumab. Best tumour response was evaluated according to modified RECIST criteria for mesothelioma (Byrne and Nowak, 2004). When response was documented at first assessment after two cycles, a confirmatory scan was needed after 4 cycles. A blood sample was obtained in a subset of patients to determine basal serum VEGF level (R\&D Systems, Quantikine Human VEGF, Minneapolis, MN, USA). Treatment toxicity was evaluated according to the NCI Common Toxicity Criteria (CTC) version 3.0 grading system. After completion of the study treatment, patients were evaluated every 3 months with chest and abdomen CT scans until disease progression, and then followed up for survival until death or last contact if still alive. Data on second-line therapies were systematically collected. Progression-free survival was defined as time from first day of study treatment until time of patient progression (as shown by radiological or clinical examination) or death from any cause. Patients without any evidence of progressive disease were censored at the date of the last follow-up. Overall survival was calculated as the time from first day of study treatment until death from any cause; patients who were alive on the date of last follow-up were censored on that date. For the final analysis, follow-up was closed at April 2012. All the data were centrally reviewed after study conclusion. 
Statistics. A single-arm, single-stage non-parametric survival design was adopted. For median survival, a Brookmeyer-Crowley like test was assumed (Karrison, 1995). Considering a median PFS of 6 months, an increase of $50 \%$ in the median survival, that is, from 6 to 9 months, was considered clinically worthwhile. Setting $\alpha$ equal to 0.10 and $\beta$ equal to 0.15 , the number of patients to be enrolled was 77. Data were described as frequencies and percentages, or as median and range when appropriated. Ninetyfive percent confidence intervals for response rates were calculated. Actuarial survival curves were generated using the method of Kaplan and Meier (1958). Median follow-up was estimated with the use of the inverse Kaplan-Meier method (Schemper and Smith, 1996). The PFS and OS were analysed according to the following variables: age, gender, histology, ECOG PS, European Organization for Research and Treatment of Cancer (EORTC) prognostic model for MPM (Curran et al, 1998) and, in a subgroup of patients, baseline serum VEGF levels. The EORTC prognostic score stratifies MPM patients in good- and poor-prognosis subgroups. Poor prognosis is associated with poor ECOG PS, high WBC count, male sex, probable diagnosis of MPM and sarcomatous histology (Curran et al, 1998). The independent value of variables was assessed in multivariate analysis using the Cox proportional hazard regression model, with an estimate of hazard ratios (HRs) (Cox, 1972). All probability values were two sided. Statistical analyses were performed using the software $R$, version 2.0.1 (R Foundation for Statistical Computing, Institute for Statistics and Mathematics, Wien, Austria).

\section{RESULTS}

Patient characteristics. Between September 2007 and October 2009, a total of 77 patients entered the study. One patient had a concomitant diagnosis of acute myeloid leukaemia before treatment start, and did not receive any study treatment. He was therefore excluded from efficacy and toxicity analysis. The characteristics of the study population are summarised in Table 1.

Efficacy. Best tumour response was assessed in 76 patients. Twenty-six patients experienced a partial response, for an objective response rate of $34.2 \%$ (95\% CI 23.7-46.0\%). Response was achieved in patients with epithelioid or mixed histotype only. Median duration of partial response was 8.0 months (range, 3.7-25.8 months). Forty-four patients (57.9\%, 95\% CI 46.0-69.1\%) achieved stable disease and $6(7.9 \%)$ were considered to have disease progression. Overall, 70 patients $(92.1 \%)$ achieved a disease control (95\% CI 83.6-97.1\%).

With a median follow-up of 34.4 months (range 1.1-44.5 months), 11 patients were still alive, 2 of them without any evidence of disease progression at 25.9 and 44.5 months. Figure 1 shows the actuarial PFS curve for the entire population; the median PFS was 6.9 months. The 1-year and 2-year estimates were $25.4 \%$ (95\% CI: $16.2-35.6 \%)$ and $8.0 \%$ (95\% CI 3.2-15.5\%), respectively. The OS curve for all enrolled patients is shown in Figure 2. The median OS was 15.3 months; the 1-year and 2-year estimates were 62.6\% (95\% CI: 50.7-72.5\%) and 25.9\% (95\% CI: $16.6-36.2 \%$ ), respectively. Patients receiving at least four treatment cycles $(n=65,85.5 \%)$ had a median PFS and OS of 8.0 and 17.6 months, respectively.

In the univariate model, a longer PFS was significantly related to epithelioid histology $(P<0.039)$ and good EORTC score $(P=0.043)$. A longer OS was associated with an epithelioid histology $(P=0.024)$, a good EORTC score $(P=0.006)$, and with ECOG PS of $0(P=0.033)$. All patients surviving longer than 2 years had a good EORTC prognostic score. However, in the multivariate model, none of the analysed variables were significantly related to either PFS or OS.

\begin{tabular}{|c|c|c|}
\hline Variable & N. of pts & $\%$ of pts \\
\hline \multicolumn{3}{|l|}{ Age } \\
\hline Median (range) & \multicolumn{2}{|c|}{$67(27-78)^{a}$} \\
\hline \multicolumn{3}{|l|}{ Gender } \\
\hline Male & 49 & 64 \\
\hline Female & 27 & 36 \\
\hline \multicolumn{3}{|c|}{ ECOG performance status } \\
\hline 0 & 58 & 76 \\
\hline 1 & 18 & 24 \\
\hline \multicolumn{3}{|c|}{ EORTC prognostic score } \\
\hline Good & 64 & 84 \\
\hline Poor & 12 & 16 \\
\hline \multicolumn{3}{|c|}{ Histological subtype } \\
\hline Epithelioid & 61 & 80 \\
\hline Sarcomatoid & 5 & 7 \\
\hline Mixed & 6 & 8 \\
\hline Unspecified & 4 & 5 \\
\hline \multicolumn{3}{|c|}{ 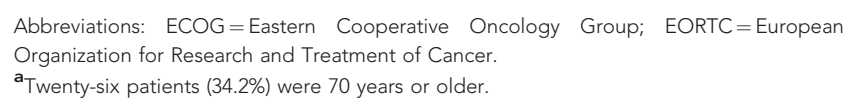 } \\
\hline
\end{tabular}

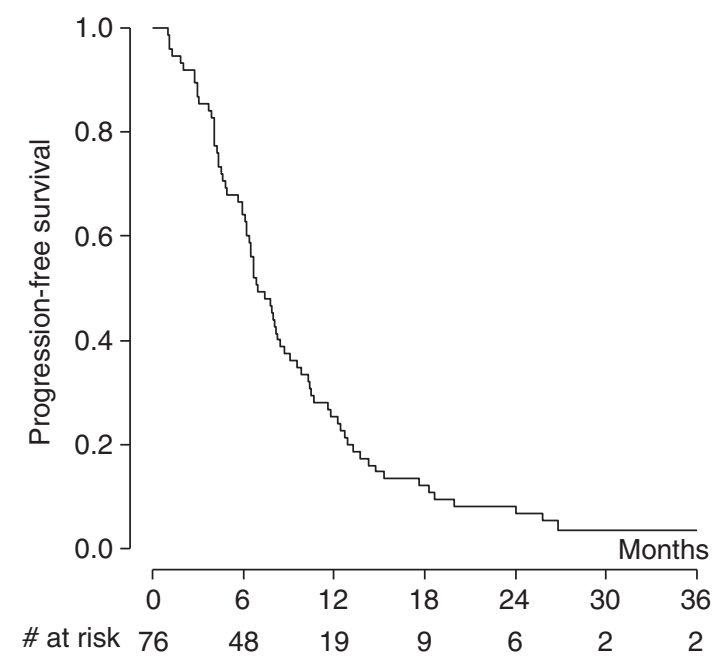

Figure 1. Kaplan-Meier curve of progression-free survival for all patients ( $n=76$; median 6.9 months).

Study drugs administration and toxicity. Patients received a median of six cycles of chemotherapy (range 1-6) plus bevacizumab; 65 (85.5\%) completed at least four cycles. Forty-eight patients (63.1\%) started maintenance bevacizumab, which was continued for a median of seven cycles (range 1-18). In two cases, maintenance bevacizumab was continued beyond 1 year (for 31 and 47 cycles, respectively), based on treating physician's decision. Dose reductions were uncommon.

Haematological toxicity was mild and consisted mostly of neutropaenia (Table 2); febrile neutropaenia was observed in two patients. Non-haematological toxicity was generally mild (Table 2); nausea/vomiting, fatigue, mucositis (stomatitis and conjunctivitis), hypertension and constipation were the most commonly reported 
adverse effects. Some severe adverse events probably related to bevacizumab were observed, as a grade 3 pulmonary embolism, a severe gastro-intestinal bleeding, and three cases of bowel perforation in three elderly patients $(75,76$ and 78 years old, respectively) without evidence of abdominal involvement by disease, or history of major abdominal surgery or comorbidities. However, all these patients had a history of diverticular disease, asymptomatic at enrollment.

Three toxic deaths occurred, one in a patient with bowel perforation, the second in a patient who died for pneumonitis with a documented H1N1 viral infection, and the third in a patient who died suddenly at home 2 weeks after the last treatment administration (autopsy was not performed). Another patient who suffered from bowel perforation died while progression free at 5 months due to complications of intestinal reconstruction.

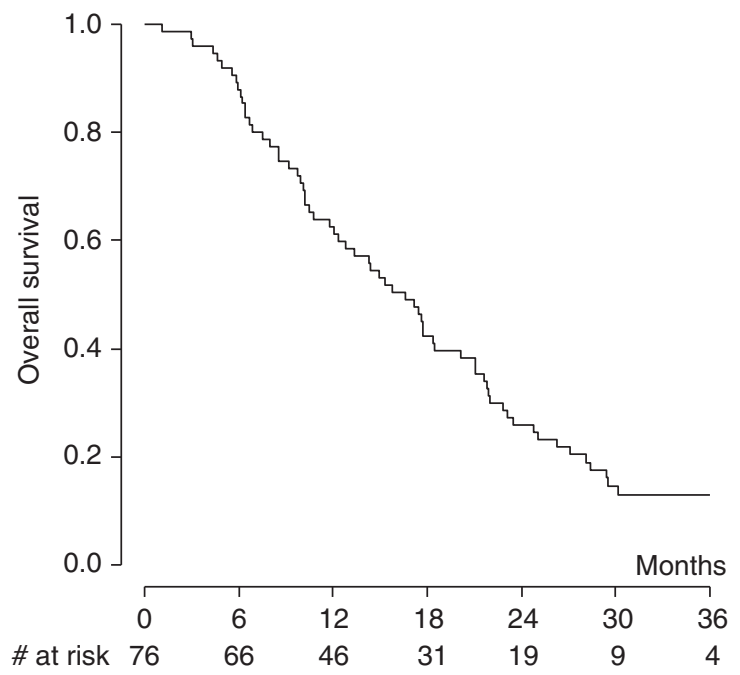

Figure 2. Kaplan-Meier curve of overall survival for all patients $(n=76$; median 15.3 months).
Post-study therapies. One patient with stable disease after six cycles of the study treatment refused maintenance bevacizumab and underwent extrapleural pneumonectomy 1 month after the last chemotherapy/bevacizumab administration; she was censored for progression at the day of last CT scan showing stable disease. Surgery was complicated by bronchopleural fistula with pleural empyema and cardiac herniation, leading to death 1 month after operation.

A second-line therapy was administered to 55 patients $(72.4 \%)$ progressing after the study treatment. Second-line regimens included gemcitabine, vinorelbine or both in most cases (26 patients), retreatment with an antifolate (pemetrexed or raltitrexed) in 14 cases, and various investigational agents in the remaining 15 patients.

Serum VEGF levels and treatment outcome. Pretreatment VEGF serum concentrations were obtained in 39 patients $(51.3 \%$ of the whole study population). The baseline characteristics of these patients were not significantly different as compared with the general population of the study, except for age that was slightly older. The mean VEGF serum level at baseline was $593 \mathrm{pg} \mathrm{ml}^{-1}$, with a very wide range of observations (from 36 to $2079 \mathrm{pg} \mathrm{ml}^{-1}$ ).

In this subgroup of patients, VEGF levels were not related to PFS (Figure 3). A significant correlation with OS was observed when VEGF was analysed as a continuous variable $(P=0.020)$, but not when VEGF values were categorised according to the median value $(P=0.110)$ (Figure 4$)$. No correlation was observed between VEGF levels and either response rate or disease control rate.

\section{DISCUSSION}

Based on a strong preclinical rationale and on the survival improvement achieved in other cancers with this treatment strategy, a great hope has been placed in the use of angiogenesis inhibitors in MPM. However, the clinical use of VEGF blockers in MPM patients has resulted more challenging than anticipated. Single-agent trials of tyrosine-kinase inhibitors, administered generally in the second-line setting, have shown disappointing

Table 2. Haematological and non-haematological toxicity by patient $(N=76)$

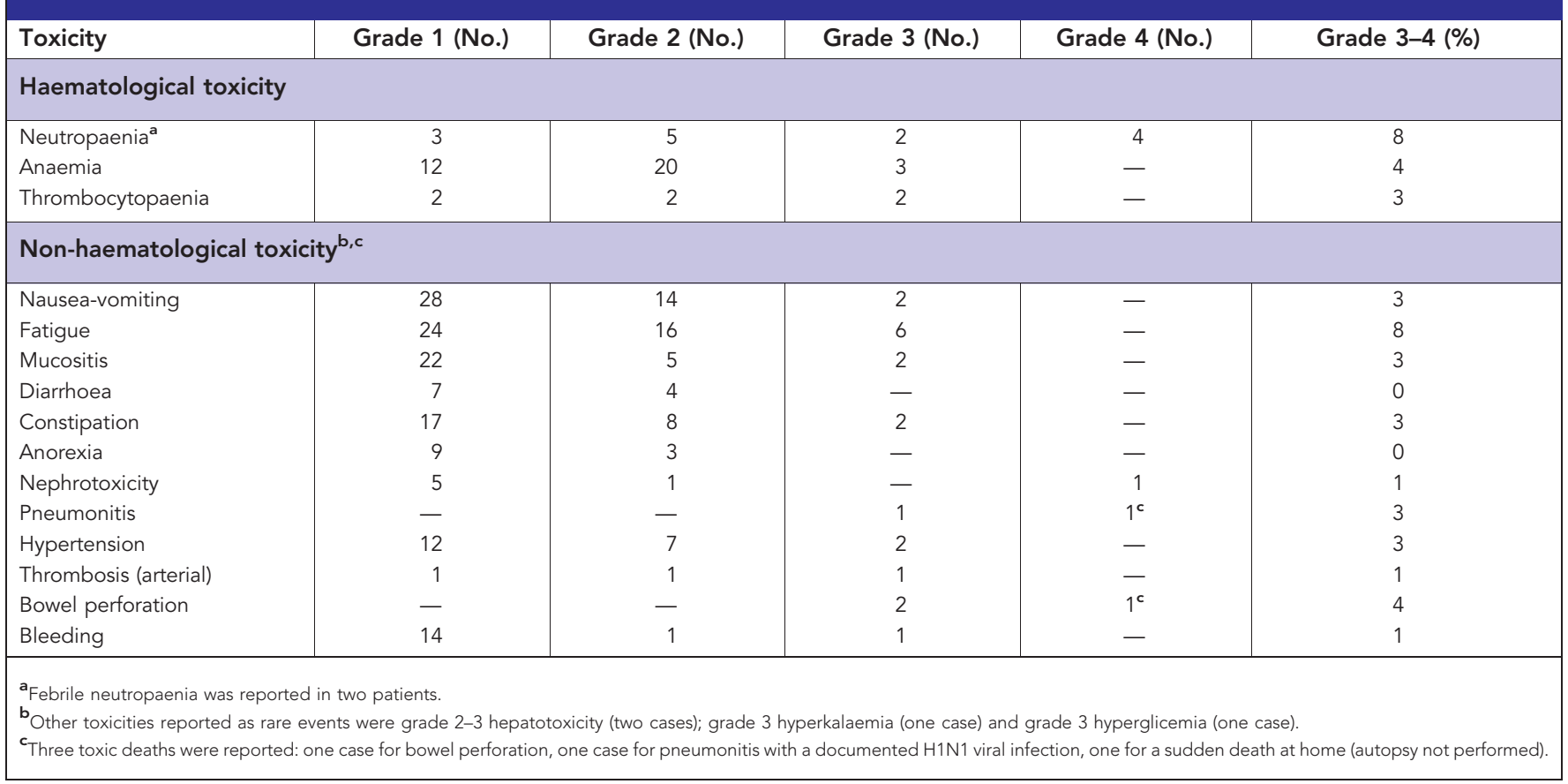


results (Ceresoli and Zucali, 2012). Maintenance therapy with thalidomide after first-line chemotherapy has failed in improving patient outcome (Baas et al, 2011).

As in other neoplasms, bevacizumab has been developed in MPM mainly in the first-line setting, in combination with chemotherapy. Recently, Kindler et al (2012) reported the final results of a randomised phase II study of cisplatin/gemcitabine plus

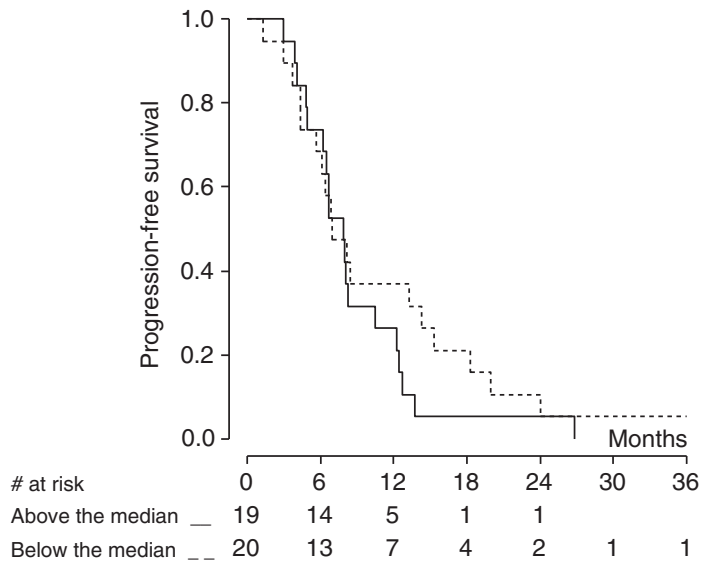

Figure 3. Kaplan-Meier curve of progression-free survival by baseline VEGF level ( $n=39$ patients). VEGF cutoff value is $593 \mathrm{pg} \mathrm{ml}^{-1}$.

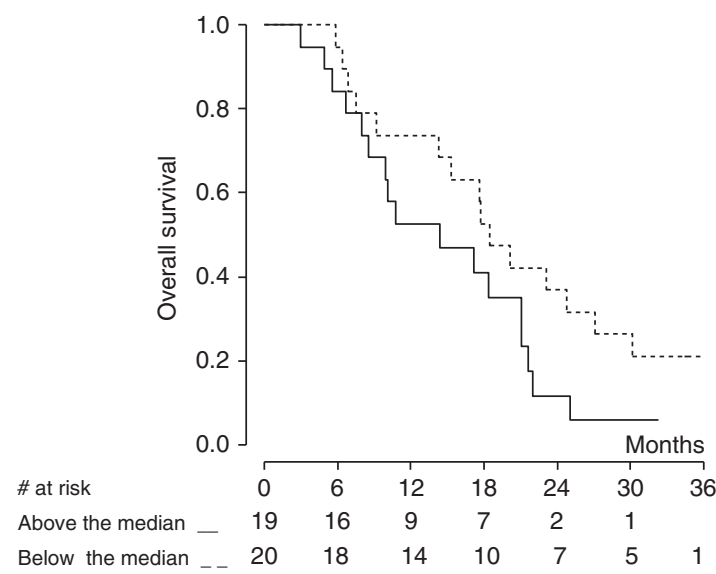

Figure 4. Kaplan-Meier curve of overall survival by baseline VEGF level ( $n=39$ patients). VEGF cut-off value is $593 \mathrm{pg} \mathrm{ml}^{-1}$. bevacizumab or placebo in patients with advanced MPM. No significant improvement was observed in response rate, PFS or OS with the addition of the angiogenesis inhibitor to chemotherapy. One of the reasons advocated by the authors to explain these disappointing results is a possible negative interaction between bevacizumab and gemcitabine, as shown in preclinical studies (Shaked et al, 2008). On the contrary, the combination of bevacizumab and pemetrexed showed therapeutic synergism in a model of orthotopically implanted human MPM cells in immunodeficient mice ( $\mathrm{Li}$ et al, 2007). Unfortunately, these promising preclinical results seem not to be confirmed in the clinical setting. Our multicentre phase II study of pemetrexed and carboplatin plus bevacizumab followed by maintenance bevacizumab failed to achieve its primary end point of a $50 \%$ improvement in median PFS in comparison with standard pemetrexed/platinum combinations (Vogelzang et al, 2003; Ceresoli et al, 2006). The median PFS of 6.9 months was identical to that reported in the above mentioned study by Kindler et al (2012) and in another single-arm phase II study of pemetrexed, cisplatin and bevacizumab (Dowell et al, 2012; Table 3). As in the other studies with bevacizumab, the median OS observed in our study (15.3 months) was better than that reported in the largest historical series with cisplatin or carboplatin and an antifolate (Vogelzang et al, 2003; Van Meerbeeck et al, 2005; Ceresoli et al, 2006; Castagneto et al, 2008). In particular, a higher proportion of 1-year survivor was observed in comparison with our previous study (Ceresoli et al, $2006)$ with pemetrexed and carboplatin alone in the same patient setting $(62.6 \%$ and $51.6 \%$, respectively). Notably, in the present study $25.9 \%$ of patients were alive at 2 years. However, these indirect comparisons must be viewed cautiously, due to different patient selection and designs of the trials, and due to the possible impact of subsequent therapies. Nearly three quarters of patients in our study received second-line treatments at disease progression, and all patients surviving longer than 2 years had a good EORTC score.

In the series reported by Kindler et al (2012), pretreatment plasma VEGF levels (obtained in 56 patients over the two treatment arms) were inversely associated with PFS and OS. In an exploratory analysis, a treatment-by-VEGF interaction was suggested; patients in the bevacizumab arm with baseline VEGF levels at or below the median had a significantly better PFS and OS, while in the high VEGF strata there were no significant differences between treatment arms. Our data confirmed the potential prognostic role of VEGF, but no difference in terms of response rate or PFS according to pretreatment serum VEGF levels was observed. Both studies have the important limitation of a small sample size. Several signalling molecules and measures of angiogenesis are under investigations, but validated biomarkers

Table 3. First-line studies with bevacizumab in MPM patients

\begin{tabular}{|c|c|c|c|c|c|c|c|}
\hline Author (reference) & $\begin{array}{l}\text { Chemotherapy } \\
\text { regimen }\end{array}$ & Phase & Status & $\mathbf{N}$ & RR/DCR & mPFS & $\mathrm{mOS}$ \\
\hline Kindler et al (2012) & Cis/gemcitabine & $\| R^{a}$ & Completed & $53^{b, c}$ & $25 \% / 76 \%$ & $6.9 \mathrm{mo}$ & $15.6 \mathrm{mo}$ \\
\hline Dowell et al (2012) & Cis/pemetrexed & II & Completed & $52^{d}$ & $40 \% / 75 \%$ & $6.9 \mathrm{mo}$ & $14.8 \mathrm{mo}$ \\
\hline Zalcman et al (2012) & Cis/pemetrexed & II-III R & Phase II completed & $47^{b}$ & $38 \% / 57 \%^{e}$ & NR & NR \\
\hline Present study & Carbo/pemetrexed & II & Completed & 76 & $34 \% / 92 \%$ & $6.9 \mathrm{mo}$ & $15.3 \mathrm{mo}$ \\
\hline \multicolumn{8}{|c|}{ 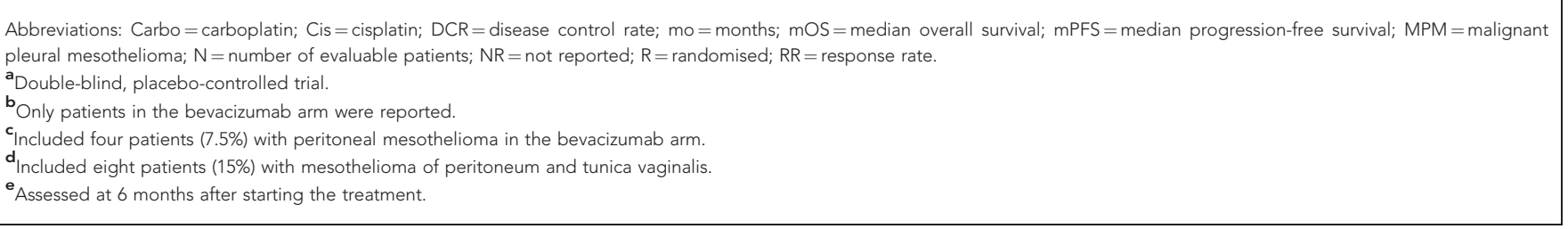 } \\
\hline
\end{tabular}


for predicting response and identifying resistant patients to anti-angiogenic therapies (particularly in MPM) are still lacking (Jain et al, 2009; Jubb and Harris, 2010; Carmeliet and Jain, 2011).

Treatment with pemetrexed, carboplatin and bevacizumab was feasible and well tolerated in most patients (Table 2). However, some severe adverse events likely related to bevacizumab, including three toxic deaths (3.9\%) and three cases of bowel perforation, were reported. Most serious adverse events occurred during the initial six cycles of therapy, with no significant increase in toxicity during maintenance bevacizumab. The rate of fatal adverse events was in the range of the reported literature (Ranpura et al, 2011). Bowel perforation has an average relative risk of 2.14 in cancer patients treated with bevacizumab (Hapani et al, 2009), varying with tumour type and drug dose. Interestingly, a higher incidence of visceral perforation was reported in two trials of non-small cell lung cancer patients treated with a regimen similar to that used in our study (Patel et al, 2009; Stevenson et al, 2012). All these patients had histories of diverticulitis, asymptomatic at enrollment. This was also the case of our patients. No case of visceral perforation was reported in the other trials with bevacizumab in mesothelioma (Jackman et al, 2008; Dowell et al, 2012; Kindler et al, 2012; Zalcman et al, 2012). In our trial, however, this adverse event was observed in three elderly patients. Several studies have recently reported a higher risk of developing severe toxicity in older patients who receive bevacizumab with chemotherapy (Ramalingam et al, 2008). Although a few surveys have found no significant correlation between the presence of diverticulosis and the risk of bowel perforation with bevacizumab (Saif et al, 2007; Abu-Hejleh et al, 2012), based on our experience we recommend to exclude at least older patients ( $\geqslant 75$ years) with a background of colonic diverticulosis from further studies with bevacizumab in MPM.

In conclusion, our study failed to achieve a significant improvement in median PFS, although a longer OS and a higher rate of long survivors were observed in comparison with historical results. However, the study has the obvious limitations of a single-arm phase II trial. Only the results of the ongoing French randomised phase II/III trial evaluating the addition of bevacizumab to pemetrexed/cisplatin (Zalcman et al, 2012) will allow to draw definite conclusions about the value of bevacizumab in MPM. Needless to say, a better understanding of the molecular alterations and key pathways that underlie resistance to VEGF-targeting treatments in cancer, with well-designed and adequately powered correlative studies, will help to establish the role, if any, of antiangiogenic therapy in this lethal disease.

\section{REFERENCES}

Abu-Hejleh T, Mezhir JJ, Goodheart JJ, Halfdanarson TR (2012) Incidence and management of gastrointestinal perforation from bevacizumab in advanced cancers. Curr Oncol Rep 14: 277-284.

Baas P, Buikhuisen W, Dalesio O, Vincent A, Pavlakis N, Van Klaveren R, Schramel F, Custers F, Schouwink H, Burgers SA (2011) A multicenter, randomized phase III maintenance study of thalidomide ( $\operatorname{arm~A}$ ) versus observation (arm B) in patients with malignant pleural mesothelioma (MPM) after induction chemotherapy. J Clin Oncol 29(suppl): (abstr 7006).

Byrne MJ, Nowak AK (2004) Modified RECIST criteria for assessment of response in malignant pleural mesothelioma. Ann Oncol 15: 257-260.

Carmeliet P, Jain RK (2011) Molecular mechanisms and clinical application of angiogenesis. Nature 473: 298-307.

Castagneto B, Botta M, Aitini E, Spigno F, Degiovanni D, Alabiso O, Serra M, Muzio A, Carbone R, Buosi R, Galbusera V, Piccolini E, Giaretto L, Rebella R, Mencoboni M (2008) Phase II study of pemetrexed in combination with carboplatin in patients with malignant pleural mesothelioma (MPM). Ann Oncol 19: 370-373.

Ceresoli GL, Zucali PA, Favaretto AG, Grossi F, Bidoli P, Del Conte G, Ceribelli A, Bearz A, Morenghi E, Cavina R, Marangolo M, Soto-Parra HJ,
Santoro A (2006) Phase II study of pemetrexed plus carboplatin in malignant pleural mesothelioma. J Clin Oncol 24: 1443-1448.

Ceresoli GL, Zucali PA, Gianoncelli L, Lorenzi E, Santoro A (2010) Second-line treatment for malignant pleural mesothelioma. Cancer Treat Rev 36: 24-32.

Ceresoli GL, Zucali PA (2012) Anti-angiogenic therapies for malignant pleural mesothelioma. Expert Opin Investig Drugs 21: 833-844.

Cox DR (1972) Regression models and life tables. J R Stat Soc B 34: 187-220.

Curran D, Sahmoud T, Therasse P, van Meerbeeck J, Postmus PE, Giaccone G (1998) Prognostic factors in patients with pleural mesothelioma: the European Organization for Research and Treatment of Cancer experience. $J$ Clin Oncol 16: 145-152.

Dowell J, Dunphy FR, Taub RN, Gerber DE, Ngov L, Yan J, Xie Y, Kindler HL (2012) A multicenter phase II study of pemetrexed, cisplatin and bevacizumab in patients with advanced malignant mesothelioma. Lung Cancer 77: 567-571.

Hapani S, Chu D, Wu S (2009) Risk of gastrointestinal perforation in patients with cancer treated with bevacizumab: a meta-analysis. Lancet Oncol 10: 559-568.

Hughes A, Calvert P, Azzabi A, Plummer R, Johnson R, Rusthoven J, Griffin M, Fishwick K, Boddy AV, Verrill M, Calvert H (2002) Phase I clinical and pharmacokinetic study of pemetrexed and carboplatin in patients with malignant pleural mesothelioma. J Clin Oncol 20: 3533-3544.

Jackman DM, Kindler HL, Yeap BY, Fidias P, Salgia R, Lucca J, Morse LK, Ostler PA, Johnson BE, Jänne PA (2008) Erlotinib plus bevacizumab in previously treated patients with malignant pleural mesothelioma. Cancer 113: 808-814.

Jain RK, Duda DG, Willett CG, Sahani DV, Zhu AX, Loeffler JS, Batchelor TT, Sorensen AG (2009) Biomarkers of response and resistance to antiangiogenic therapy. Nat Rev Clin Oncol 6: 327-338.

Jubb AM, Harris AL (2010) Biomarkers to predict the clinical efficacy of bevacizumab in cancer. Lancet Oncol 11: 1172-1183.

Kaplan EL, Meier P (1958) Nonparametric estimation of incomplete observations. J Am Stat Assoc 53: 457-481.

Karrison T (1995) Comparison of median survival times with adjustment for covariates. Stat Med 14: 2537-2553.

Kindler HL, Karrison TTG, Gandara DR, Lu C, Krug LM, Stevenson JP, Jänne PA, Quinn DI, Koczywas MN, Brahmer JR, Albain KS, Taber DA, Armato 3rd SG, Vogelzang NJ, Chen HX, Stadler WM, Vokes EE (2012) Multicenter, double-blind, placebo-controlled, randomized phase II trial of gemcitabine/cisplatin plus bevacizumab or placebo in patients with malignant mesothelioma. J Clin Oncol 30: 2509-2515.

Kumar-Singh S, Weyler J, Martin MJ, Vermeulen PB, Van Marck E (1999) Angiogenic cytokines in mesothelioma: a study of VEGF, FGF-1 and -2, and TGF beta expression. J Pathol 189: 72-78.

Li Q, Yano S, Ogino H, Wang W, Uehara H, Nishioka Y, Sone S (2007) The therapeutic efficacy of anti-vascular endothelial growth factor antibody, bevacizumab, and pemetrexed against orthotopically implanted human pleural mesothelioma cells in severe combined immunodeficient mice. Clin Cancer Res 13: 5918-5925.

Patel JD, Hensing TA, Rademaker A, Hart EM, Blum MG, Milton DT, Bonomi PD (2009) Phase II study of pemetrexed and carboplatin plus bevacizumab with maintenance pemetrexed and bevacizumab as first-line therapy for nonsquamous non-small-cell lung cancer. J Clin Oncol 27: 3284-3289.

Ramalingam SS, Dahlberg SE, Langer CJ, Gray R, Belani CP, Brahmer JR, Sandler AB, Schiller JH, Johnson DH (2008) Outcomes for elderly, advanced-stage non small-cell lung cancer patients treated with bevacizumab in combination with carboplatin and paclitaxel: analysis of Eastern Cooperative Oncology Group Trial 4599. J Clin Oncol 26(60): 65.

Ranpura V, Hapani S, Wu S (2011) Treatment-related mortality with bevacizumab in cancer patients. JAMA 305: 487-494.

Saif MW, Elfiki A, Salem RR (2007) Gastrointestinal perforation due to bevacizumab in colorectal cancer. Ann Surg Oncol 14: 1860-1869.

Santoro A, O'Brien ME, Stahel RA, Nackaerts K, Baas P, Karthaus M, Eberhardt W, Paz-Ares L, Sundstrom S, Liu Y, Ripoche V, Blatter J, Visseren-Grul CM, Manegold C (2008) Pemetrexed plus cisplatin or pemetrexed plus carboplatin for chemonaive patients with malignant pleural mesothelioma: results of the International Expanded Access Program. J Thorac Oncol 3: 756-763.

Schemper M, Smith TL (1996) A note on quantifying follow-up in studies of failure time. Control Clin Trials 17: 343-346. 
Shaked Y, Henke E, Roodhart JML, Mancuso P, Langerberg MH, Colleoni M, Daenen LG, Man S, Xu P, Emmenegger U, Tang T, Zhu Z, Witte L, Strieter RM, Bertolini F, Voest EE, Benezra R, Kerbel RS (2008) Rapid chemotherapy-induced acute endothelial progenitor cell mobilization: implications for antiangiogenic drugs as chemosensitizing agents. Cancer Cell 14: 263-273.

Scherpereel A, Astoul P, Baas P, Berghmans T, Clayson H, de Vuyst P, Dienemann H, Galateau-Salle F, Hennequin C, Hillerdal G, Le Péchoux C, Mutti L, Pairon JC, Stahel R, van Houtte P, van Meerbeeck J, Waller D, Weder W (2010) Guidelines of the European Respiratory Society and the European Society of Thoracic Surgeons for the management of malignant pleural mesothelioma. Eur Resp J 35: 479-495.

Stevenson JP, Langer CJ, Somer RA, Evans TL, Rajagopalan K, Krieger K, Jacobs-Small M, Dyanick N, Milcarek B, Coakley S, Walker S, Eaby-Sandy B, Hageboutros A (2012) Phase 2 trial of maintenance bevacizumab alone after bevacizumab plus pemetrexed and carboplatin in advanced, nonsquamous nonsmall cell lung cancer. Cancer 118: 5580-5587.

Strizzi L, Catalano A, Vianale G, Orecchia S, Casalini A, Tassi G, Puntoni R, Mutti L, Procopio A (2001) Vascular endothelial growth factor is an autocrine growth factor in human malignant mesothelioma. J Pathol 193: $468-475$.

Tsao AS, Wistuba I, Roth JA, Kindler HL (2009) Malignant pleural mesothelioma. J Clin Oncol 27: 2081-2090.

Van Meerbeeck JP, Gaafar R, Manegold C, Van Klaveren RJ, Van Marck EA, Vincent M, Legrand C, Bottomley A, Debruyne C, Giaccone G (2005) Randomized phase III study of cisplatin with or without raltitrexed in patients with malignant pleural mesothelioma: an intergroup study of the European Organization for Research and Treatment of Cancer Lung
Cancer Group and the National Cancer Institute of Canada. J Clin Oncol 23: 6881-6889.

Vogelzang NJ, Rusthoven JJ, Symanowski J, Denham C, Kaukel E, Ruffie P, Gatzmeier U, Boyer M, Emri S, Manegold C, Niyikiza C, Paoletti P (2003) Phase III study of pemetrexed in combination with cisplatin versus cisplatin alone in patients with malignant pleural mesothelioma. J Clin Oncol 21: 2636-2644.

Yasumitsu A, Tabata C, Tabata R, Hirayama N, Murakami A, Yamada S, Terada T, Iida S, Tamura K, Fukuoka K, Kuribayashi K, Nakano T (2010) Clinical significance of serum vascular endothelial growth factor in malignant pleural mesothelioma. J Thorac Oncol 5: 479-483.

Zalcman G, Mazieres J, Scherpereel A, Margery J, Moro-Sibilot D, Parienti JJ, Gounant V, Riviere A, Monnet I, Molinier O, Lena H, Friard S, Duhamel JP, Audigier-Valette C, Robinet G, Creveuil C, Ligeza-Poisson C, Morin F (2012) IFCT-GFPC-0701 MAPS trial, a multicenter randomized phase II-III trial of pemetrexed-cisplatin with or without bevacizumab in patients with malignant pleural mesothelioma. J Clin Oncol 30(suppl): abstr TPS7112)

Zucali PA, Ceresoli GL, De Vincenzo F, Simonelli M, Lorenzi E, Gianoncelli L, Santoro A (2011) Advances in the biology of malignant pleural mesothelioma. Cancer Treat Rev 37: 543-558.

This work is published under the standard license to publish agreement. After 12 months the work will become freely available and the license terms will switch to a Creative Commons AttributionNonCommercial-Share Alike 3.0 Unported License. 